\title{
Farmer's Perception Towards Agricultural Technology - The Case of Improved Highland Maize Varieties Adoption in Selected Kebeles of Toke Kutaye District, Oromia Regional State, Ethiopia
}

\author{
Dawit Milkias $^{1}$, , Daniel Belay ${ }^{2}$, Gemechu Shale Ogato $^{2}$ \\ ${ }^{1}$ Ambo Agricultural Research Center, Ethiopian Institute of Agricultural Research/EIAR/, Ambo, Ethiopia \\ ${ }^{2}$ Department of Rural Development and Agricultural Extension, Institute of Cooperatives and Development Studies, Ambo University, \\ Ambo, Ethiopia
}

Email address:

mkdave04@gmail.com (D. Milkias)

${ }^{*}$ Corresponding author

To cite this article:

Dawit Milkias, Daniel Belay, Gemechu Shale Ogato. Farmer's Perception Towards Agricultural Technology - The Case of Improved Highland Maize Varieties Adoption in Selected Kebeles of Toke Kutaye District, Oromia Regional State, Ethiopia. Journal of World Economic Research. Vol. 8, No. 1, 2019, pp. 1-7. doi: 10.11648/j.jwer.20190801.11

Received: February 28, 2019; Accepted: April 9, 2019; Published: April 29, 2019

\begin{abstract}
The study aims to reveal farmer's perceptions towards improved highland maize varieties in selected kebeles of Toke kutaye districts. In this paper, farmer's perception towards improved highland maize varieties were investigated or measured using a scale with items developed for the purpose of this study. Two stage sampling procedures were followed in order to draw 150 sample respondents. Responses of sample respondents on the perception related were analyzed using Likert type scale. Based on the level of agreements the result revealed that perception on disease resistant, high yielding potential of the varieties, early maturity of the varieties, agro ecological suitability and availability of seed at the right time and quality showed relatively best performance of the varieties in the study area. Whereas, perception on technological availability of the varieties indicates relatively poorest agreement compared to all other characteristics of level of agreements considered. Even if the advantages of the varieties are more for households of the study area, some farmers are discouraged to adopt the variety because of reasons such as demand more inputs, the lack of credit service, market problem, insect pest problem, lack of awareness and extension support on the technology. Therefore, the extension and research system have to look in to these factors to give solution for the adoption of the variety.
\end{abstract}

Keywords: Highland Maize, Perception, Likert Type Scale, Agreements

\section{Introduction}

Food security is a major socio-political issue in Ethiopia, and elsewhere in Africa. Its economic wellbeing is also dependent on the success of its agriculture. Ethiopia has long suffered from food shortages and economic under development even though it is endowed with a wide range of crop and agro-ecological diversity. Maize, teff, sorghum, wheat, and barley among cereals and enset (Ensete ventricosum) among "roots and tubers" provide the main calorie requirements in the Ethiopian diet.

Maize has expanded rapidly and transformed production systems in Africa as a popular and widely cultivated food crop since its introduction to the continent around 1500 A.D. according to [11] cited in [15]. The production system in the 1960 s and for the first quarter of 1970s was truly subsistence, the yields barely exceeding 1 metric ton (MT)/ha. The rate of growth for area declined following the great drought of 1974, and while there was expansion in the 1980s, the average annual yield was volatile and rarely exceeded $1.5 \mathrm{MT} / \mathrm{ha}$. Maize production and its status in determining food security in the country received a major focus in the mid-1980s, particularly spurred by the 1984 devastating drought and the famine that followed. The wide adaptability of the crop and 
the potential to produce more calories and food per area of land cultivated than all major cereals grown in Ethiopia were important factors in considering maize as part of the national food security strategy, including its inclusion under the government-led intensive agricultural extension program. With increased production driving market prices down, maize became more affordable (e.g., relative to other staples such as teff and wheat) to rural and urban consumers. It is now increasingly used both separately as well as in mixed flour with other more expensive cereals in traditional Ethiopian diets.

Maize is the most important staple in terms of calorie intake in rural Ethiopia. The 2004/5 national survey of consumption expenditure indicated that maize accounted for $16.7 \%$ of the national calorie intake followed by sorghum $(14.1 \%)$ and wheat $(12.6 \%)$ among the major cereals [4]. Compared to the 1960 s the share of maize consumption among cereals more than doubled to nearly $30 \%$ in the 2000 s, whereas the share of teff, a cereal that occupies the largest area of all crops in Ethiopia, declined from more than $30 \%$ to about $18 \%$ during the same period [7].

The popularity of maize in Ethiopia is partly because of its high value as a food crop as well as the growing demand for the stover as animal fodder and source of fuel for rural families. Approximately $88 \%$ of maize produced in Ethiopia is consumed as food, both as green and dry grain. Maize for industrial use has also supported growing demand. Very little maize is currently used as feed but this too is changing in order to support a rapidly growing urbanization and poultry industry. Unlike its neighbor, Kenya, which imports a significant share for its consumption needs, Ethiopia has increasingly attained self-sufficiency in maize production since early this decade and even exports some quantities to neighboring countries (e.g., Sudan and Djibouti) in years of surplus production [15]. If production can be significantly expanded, the potential for maize export to all the neighboring countries including Kenya is very high although the national demand is expected to continue to grow in the coming years.

High land maize is one of the major food crops where research brought tangible improvement in production and productivity $[8,16]$. However, in sub-humid agro ecology, smallholder farmers' knowledge and use of agricultural technologies in general and improved highland maize varieties in particular, are limited due to various factors that are either internal or external to the farmers' circumstances. In West Showa Zone the national agricultural research system has generated a number of improved technologies and recommendations such as crop variety, agronomic practices, crop protection measures as well as other technical advises and practices.

In Toke kutaye district improved highland maize technologies are being promoted by research center. The technologies promoted include improved highland maize varieties, recommended fertilizer rates and types, improved agronomic and weed control practices. Having implemented many interventions, this study was mainly done to know the profile of farmer respondents and to examine their perception towards improved highland maize varieties, in the study area. The overall objectives of the study were to identify the farmers' perceptions towards the adoption of new highland maize varieties and provide policy recommendation towards the varieties in the study area.

\section{Empirical Studies on the Adoption of Agricultural Technologies}

Adoption of improved agricultural technology is crucial to increase agricultural productivity to meet food demand and ensure food security in developing countries. Productivity improving technology facilitates the growth of agro processing enterprises thereby transforming the low productivity subsistence agriculture to a high productivity agro industrial economy [9]. However, many small holders in developing countries have not been able to use improve crop technology and to realize the full potential of agricultural productivity. Technologies play an important role in economic development. Adoption and diffusion of technology are two interrelated concepts describing the decision to use or not use and the spread of a given technology among economic units over a period of time. Adoption of any innovation is not a one step process as it takes time for adoption to complete. First time adopters may continue or cease to use the new technology. The duration of adoption of a technology vary among economic units, regions and attributes of the technology itself. Therefore, adequate understanding of the process of technology adoption and its diffusion is necessary for designing effective agricultural research and extension programs.

Many studies have focused on the relationships of key variables to the adoption behavior of farmers. A review of previous studies is important as it provides some conceptual and theoretical basis for identifying the relevant variables to be included in the analysis. Farmers' subjective perceptions of new technologies in light of prevailing socioeconomic environment condition their adoption behavior. The concept of adopter perception can now be found in varied agricultural economics literature [2]. It is well known that farmers often fail to follow the technical advice provided by the extension services and do not always adopt technical innovations [5]. This makes assessing the factors that can enhance innovation of the adoption of useful step to accept appropriate technology development and suitable policy strategies to improve the likelihood of adoption of innovations entailing lower chemical input use. Additionally, farmer's expectations about future policy and market change can play an important role as they can modify farmer's perceived utility of innovations. The effectiveness numerous determinants related to farmer's personal attitudes toward risk, change and uncertainty which can significantly influence adoption as they can reduce the perceived utility of innovations, and be associated with aversion to change [1]. Adoption also affected with production inputs and constraints such as 
financial capacities, access to water resources, farm size [3]. These contexts are mainly captured through geographical indicators such as regional appurtenance, distance to other innovators and distance to market, demographic pressure, and the presence of extension services [10]. They are also related to farmers' characteristics such as the number of contacts with extension agents, the involvement of farmers in research programs, or the affiliation to a farmer's union. Generally, adoption is determined by different factors like policy and market change, attitude towards risk and other factors.

Many studies have focused on the relationships of key variables to the adoption behavior of farmers. A review of previous studies is important as it provides some conceptual and theoretical basis for identifying the relevant variables to be included in the analysis. The category variables are the most common household characteristics which are mostly related with farmers' adoption behavior. Age, education and farming experience have been reviewed in this study. Different agricultural technology adoption studies revealed conflicting results on the influence of age in adoption. The study conducted by [12] on factors affecting adoption of improved maize seed and fertilizer in northern Tanzania, indicated that farmer's age did not significantly influence improved technology adoption.

Quantitative studies that have considered farmers' perception in context of adoption decisions have included farmers' perception of new technology. Farmers are considered to have subjective preferences for specific characteristics inherent in new technologies or innovations. These preferences are assumed to play a significant role in technology adoption. Adoption of technologies by farmers reflects rational decision making based up on farmers perceptions of appropriateness of the characteristics of the technology under investigation.

A large number of personal, situation and social characteristics of farmers have been found to be related to their adoption behavior [14]. Based on this idea, [6] tried to compare the adoption behavior of both adopters and nonadopters. Adopters of farming practices tend to be middle aged, have a high rate of literacy and a higher level of formal education, operate large sized holdings, own the land they operate, have a relatively high income and economic status, are commercial in farming orientation, have relatively high level of social participation, and tend to be cosmopolite in orientation, have relatively high level of extension contact, and belong to upper socio-economic status categories. Nonadopters, on the other hand, are relatively old in age, have a low rate of literacy and level of formal education, operate smallholdings, are mostly share-croppers or small and marginal farmers, belong to low income and economic status, have a subsistence orientation to farming, have a low level of extension contact, and come from low socioeconomic status categories.

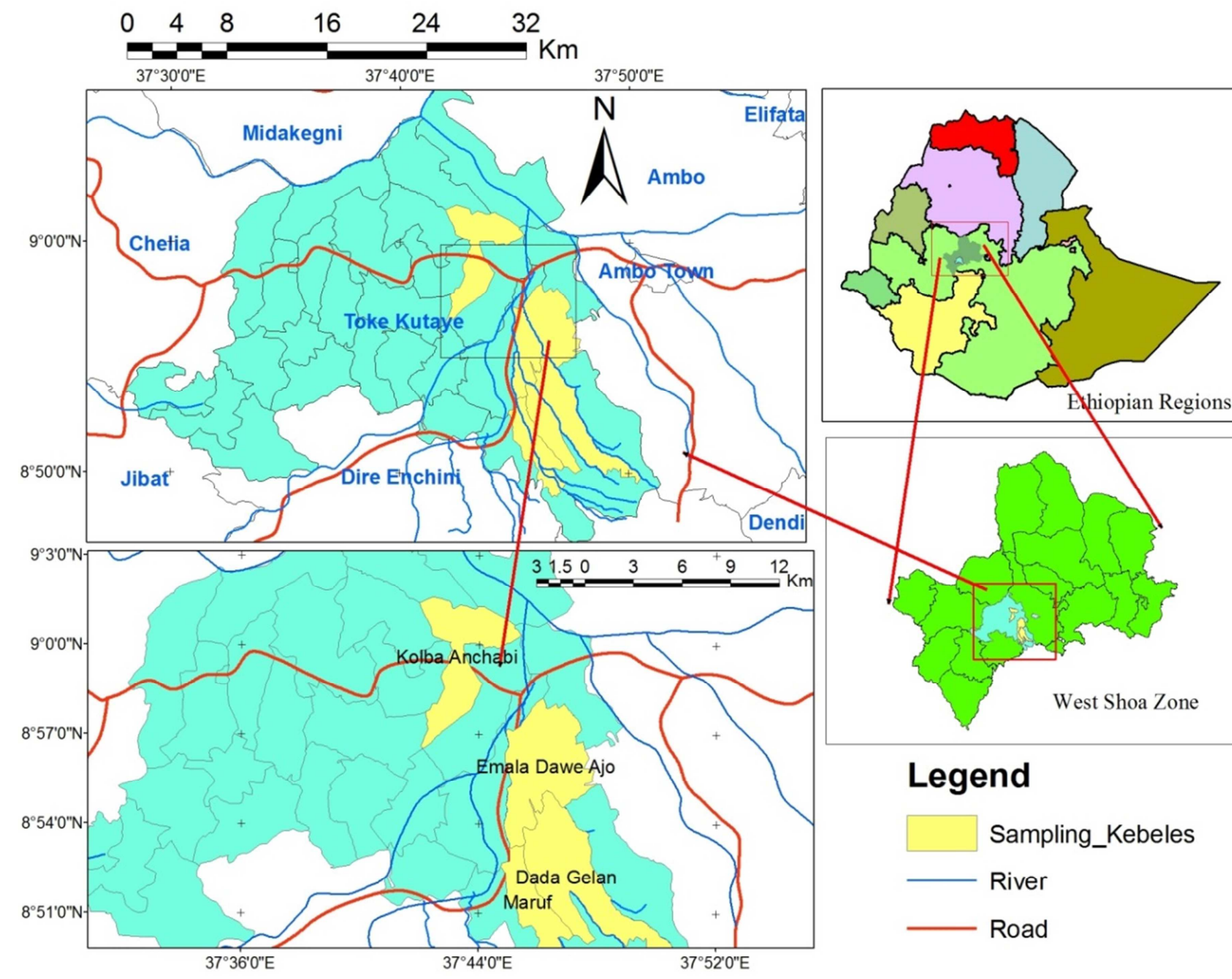

Figure 1. Map of the study area. 


\section{Methodology of the Study}

\subsection{Description of the Study Area}

The study was conducted in Oromia Region, West Shoa Zone, Toke Kutaye district which is located west of Addis Ababa at a distance of $128 \mathrm{~km}$ and $12 \mathrm{~km}$ west from the capital town of West Shoa Zone, Ambo. Geographically, it lies between $8^{\circ} 47^{\prime}$ to $9^{\circ} 21$ latitudes and $37^{\circ} 32$ to $37^{\circ} 03^{\prime} \mathrm{E}$ longitude. The district borders with Midakegn district in the North, Dirre Inchini in the South, Ambo district in the East and Chalia district in the West. The district contains 24 kebeles (20 rural and 4 urban kebeles). The total amount of population is 134,767 (66,492 males and 68,275 female). There are $22,895 \mathrm{HH}$ farmers in the district, out of these 20,148 male and 2747 females. The district is estimated about $788.87 \mathrm{~km}^{2}$, accounting for $10.7 \%$ of the total area of West Shoa Zone.

The land use pattern of the district shows that 37,509 ha is cultivated land; 3651 ha is covered with forest, 11,603 ha is grazing land and 26,124 ha with bush and shrubs. The district consists of $27 \%$ arid, $55 \%$ Semi-arid and $18 \%$ desert areas. The major crops produced in the district are Teff, Maize, wheat, Sorghum, barley and others [17]. The maximum and minimum altitudes of the study area are 1880 and 3194 m.a.s.l. respectively. Annual rainfall is between 800 and $1100 \mathrm{~mm}$. The minimum and maximum temperature are $10^{\circ} \mathrm{C}$ and $29^{\circ} \mathrm{C}$ respectively. The soil characteristics are $48 \%$ red soil, $27 \%$ black soil, $25 \%$ red and black mixture. The total livestock, posses 331,134 . The total area of land that can be used for irrigation is $3,048 \mathrm{ha}$, from this area 1665 he is currently being used [17].

\subsection{Sampling Procedure and Sample Size Determination}

Two stage sampling techniques were employed to select the sample respondents. First stage was purposive selection of highland maize growing Kebeles of the districts, followed by selection of sample households. The Kebele identification was made through reviewing secondary data on production potential of maize and dissemination of the improved highland maize technologies and area coverage of the crop. In the second stage 150 sample respondents were chosen using systematic random sampling technique from each kebeles based on probability proportional to size through using the following formula of sample determination:

$$
\begin{gathered}
n=\frac{N}{1+N(e) 2} \\
n=\frac{3954}{1+3954(0.08)} \approx 150
\end{gathered}
$$

Where $\mathrm{n}$ is the sample size for the study, $\mathrm{N}$ is the total households of the study area which is $3954, e$ is the maximum variability or margin of error or which is 0.08 in this study, 1 is the probability of the event occurring. The sample size from each kebeles was determined based on their proportion to total share of households residing in each kebeles.
Table 1. Sample households to be selected for the study.

\begin{tabular}{llll}
\hline No. & Sample kebeles & Households & Sample size \\
\hline 1 & Kolba anchabi & 550 & 21 \\
2 & Maruf & 1031 & 39 \\
3 & Dadagalan & 1123 & 43 \\
4 & Imala Dawo Ajo & 1250 & 47 \\
& Total & 3954 & 150 \\
\hline
\end{tabular}

Source: Author's compilation, 2017

Focus Group Discussions (FGD)

For this study one focus groups contain eight members was conducted with active household heads in each selected villages. The purpose of the focus group discussion was to generate in-depth information on some of the survey findings and perceptions of the farmers that may not have been adequately captured by the semi-structured questionnaires. The researcher presented various open-ended questions regarding adoption and perceptions on the varieties and other related factors to the discussants to express their own perceptions and response. This technique enabled the researcher to explore what they know or think about the research problem that the questions would cover, and then to verify, confirm and add depth to the results of the household survey.

\subsection{Data Analysis}

Farmers perception towards improved highland maize variety is described and measured based on the agreement level of the respondents perceived during the data collection. Perception was measured using a scale with items developed for the purpose of this study. Responses of sample respondents on the perception related were analyzed using Likert type scale.

Accordingly, the ratings such as strongly disagree(1), disagree(2), neutral(3), agree(4) and strongly agree(5) were used to measure the respondents perception to the technologies and the larger value(5) indicates how farmer perceives the characteristics being presented for evaluation is being embodied and 4,3,2, and 1 in a decreasing manner. A value less than three indicates how the farmer perceives the characteristics under evaluation as poor or negatively. The relative agreement was computed by dividing the mean of each variable to the total mean and multiplied by $100 \%$.

\section{Result and Discussion}

\subsection{Adoption of Improved Highland Maize Varieties in the Study Area}

Improvement in production and productivity of a given crop depends, among other things, on presence and use of better and improved varieties. In line with this objective, a lot of efforts have been made by the research system to generate improved varieties of highland maize varieties and as a result, many varieties have been released. Among the released, AMB02SYN1- 'Hora', AMH800-'Arganne', AMH850'Wenchi', AMH851-'Jibat', and AMH760-'Webi' varieties were introduced to the study area [8]. These all varieties were 
introduced to the farming community through Ambo agricultural Research Center, MoA and other organizations.

Regardless of such intervention, however, adoption of improved high land maize varieties in the study area is still low. The level of adoption of improved high land maize variety influences the amount of yield obtained by farmers. Data set contains 150 farm households and of these, about $104(69.33) \%$ households were adopters and about 46 $(30.67 \%)$ households were non-adopters. Farmers who did not grow improved highland maize variety were considered as non-adopters and while the farmers who grow at least one of the improved highland maize varieties during the 2016 cropping season with some of the recommended agronomic practices (improved variety, seed rate, and fertilizer application rate) were taken as adopters.

In the study area, the average land used for improved highland maize was 0.3125 ha, and the minimum and maximum land coverage for improved highland maize was 0.125 ha and 0.5 ha respectively. The average yield obtained was 11 quintal per hectare and the maximum was 18 quintal while the minimum was 4 quintal. The average gross income from improved highland maize production of the sample adopter households from one season harvesting time 2016/17 production year was $3590 \mathrm{ETB}$, i.e. the minimum and maximum income was 880 ETB and 6300 ETB respectively.

\section{Results of Focus Group Discussion (RFGD)}

Finding from focus group discussion confirmed that the newly released varieties were used to increase production and productivity of the farmers. The reason for few farmers using the new varieties were due to lack of the varieties on time, lack of credit, market problem and lack of enough extension support from development agents were the major problems in the area. FGD discussion explained the role played by women in highland maize cultivation as very crucial. According to farmers of the study area, women role is not restricted to biological, labor and social reproduction; they are also involved in productive role of farming activities. Although they were found to participate in different activities of production process such as sowing, weeding, cultivation, harvest, transport, storage and preparation of threshing field, the nature of participation is not full time because of biological reproduction of child birth and lactation and laborer production which involves the daily regeneration of the labor force through cooking, cleaning, washing, nursing and so on. Making female farmers targets in extension, therefore, makes sense for agricultural and rural development. The focused groups at each study area described important constraints to maize production. The groups also identified and listed the major constraints recognized and agreed on by most participants in the sampled kebeles. The constraints were seed \& high cost of inorganic fertilizers, weak extension services, Wild and domestic animals, weevils, rodents, low maize price and instability of maize price were among the constraints.

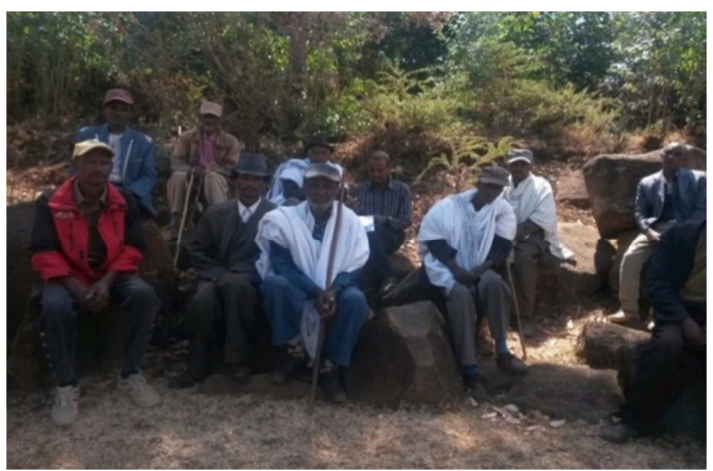

Figure 2. FGD at Kolba Anchabi Kebele.

\subsection{Perception on Improved Highland Maize Variety Related Analysis Results}

Technologies are viable only when farmers use them. No matter how well the new technologies work on research stations, if farmers do not have them for use, their development would be in vain [13] cited in [14]. But more trouble will it have been if the farmers' perception of the technologies is not only low but also wrong [14]. Farmers perception towards highland maize variety is described and measured based on the agreement level of the respondents perceived during the data collection. Perception was measured using a scale with items developed for the purpose of this study. Responses of sample respondents on the perception related were analyzed using Likert type scale. Accordingly, the ratings such as strongly disagree (1), disagree (2), no opinion (3), agree (4) and strongly agree (5) were used to measure the respondents perception to the technologies and the larger value (5) indicates how farmer perceives the characteristics being presented for evaluation is being embodied and 4,3,2, and 1 in a decreasing manner. A value less than three indicates how the farmer perceives the characteristics under evaluation as poor or negatively.

Table 2. Farmers 'perception on highland maize technology.

\begin{tabular}{|c|c|c|c|c|c|c|c|c|}
\hline \multirow{2}{*}{ Level of agreement on IHM Varieties } & \multicolumn{5}{|c|}{ Distribution of respondents per perception category (\%) } & \multirow{2}{*}{ Mean } & \multirow{2}{*}{$\begin{array}{l}\text { Level of } \\
\text { agreement (\%) }\end{array}$} & \multirow{2}{*}{ Rank } \\
\hline & Strongly Disagree & Disagree & Neutral & Agree & Strongly Agree & & & \\
\hline Technological availability of IHMV & 24.67 & 41.33 & 3.33 & 21.33 & 9.33 & 2.5 & 12.83 & 6 \\
\hline Perception on disease resistant capability & 8 & 26.67 & 3.33 & 55.33 & 6.67 & 3.26 & 16.73 & 5 \\
\hline High yielding potential of the varieties & 8 & 19.33 & 6 & 54.67 & 12 & 3.43 & 17.6 & 2 \\
\hline Early maturity of the varieties & 4 & 24 & 8.67 & 60 & 3.33 & 3.35 & 17.2 & 3 \\
\hline Agro ecological suitability & 6.67 & 28.67 & 6 & 42.67 & 16 & 3.33 & 17.04 & 4 \\
\hline Availability of seed at the right time and quality & 2.01 & 20.13 & 7.38 & 55.03 & 15.44 & 3.62 & 18.6 & 1 \\
\hline Sum of Mean & & & & & & 19.49 & 100 & \\
\hline Grand Mean & & & & & & 3.25 & & \\
\hline
\end{tabular}

Source: survey data, 2017: 
In the study area the sampled respondent's perception on improved highland maize varieties were evaluated with the help of the aforementioned analytical framework. A grand mean of 3.25 (maximum=5; minimum=1) indicates that the overall perception on level of agreement on the varieties were showed relatively best performance depending on the characteristics among adoption categories. From the level of agreement of improved highland maize varieties, perception on disease resistant, high yielding potential of the varieties, early maturity of the varieties, agro ecological suitability and availability of seed at the right time and quality showed relatively best performance of the varieties in the study area. Whereas, perception on technological availability of the varieties indicates relatively poorest agreement compared to all other characteristics of level of agreements considered.

The survey result indicated that, the majority of the sample households perceived that they have adopted the variety due to the above level of agreement over the other as predicted. Even if the advantages of the varieties are more for households of the study area, some farmers are discouraged to adopt the variety because of reasons such as demand more inputs, the lack of credit service, market problem, insect pest problem, lack of awareness and extension support on the technology. Therefore, the extension and research system have to look in to these factors to give solution for the adoption of the variety.

\section{Conclusion and Policy Recommendation}

\subsection{Conclusion}

As repeatedly stated improved highland maize varieties production is important in solving food security and poverty problems in agriculture-based economies demand for substantial efforts in improving agricultural production and productivity. From the level of agreement of improved highland maize varieties, perception on disease resistant, high yielding potential of the varieties, early maturity of the varieties, agro ecological suitability and availability of seed at the right time and quality showed relatively best performance of the varieties in the study area. Whereas, perception on technological availability of the varieties indicates relatively poorest agreement compared to all other characteristics of level of agreements considered.

This study was limited in terms of perception on highland maize varieties that were considered at the household level. Only highland maize varieties were examined yet many other improved cereal crops have been introduced in the study area. In future research, it is recommended that more agricultural technologies introduced to farmers in a particular area be examined using the same criteria used in this study, in which case they can be ranked in terms of suitability using both conjoint results and farmer scoring of the agricultural technologies in the particular attributes.

\subsection{Policy Implications}

Farmers are more responsive in adopting improved highland maize varieties if they perceive that those new varieties as compared to the existing varieties give higher grain yield and earliness of the varieties. Despite the significant changes, there are unexploited opportunities for further increasing highland maize productivity and production in study area as well as on the same agro ecologies of Ethiopia. Most importantly, a significant portion of the maize area is yet to be reached with modern innovations and several new hybrids are yet to be integrated into the seed production and extension systems. The public sector extension programs currently coordinate the provision of credit and the supply of inputs, including seed, fertilizer and credit. Part of this service needs to be privatized (including farmers 'cooperatives) so that extension workers can focus on farmer education and innovation. The conventional top-down and supply-driven approaches for extension still remain across the country and this needs to quickly give way to provision of efficient services in terms of information, knowledge, and skills, and facilitation of linkages with other institutional support services of input supply, credit service, and output marketing. Therefore, policy makers and government intervention related with agricultural technology transfer should take significantly influenced level of agreements into consideration.

\section{References}

[1] Abadi Ghadim, A. K., Pannell, D. J. and Burton, M. P. 2005. Risk, uncertainty and learning in adoption of a crop innovation. Agricultural Economics, 33:1-9.

[2] Adesina, A. A. and M. M. Zinnah. 1993. Farmer Perceptions and Adoption Decisions: A Tobit Model Application in Sierra Leone. Agricultural Economics, 9: 297-311.

[3] Adesina, A. A. and Chianu J. (2002). Determinants of farmers' adoption and adaptation of alley farming technology in Nigeria. Agroforestry System 55: 255-265.

[4] Berhane, G., Paulos, Z., Tafere, K., \& Tamru, S. (2011). Food grain consumption and calorie intake patterns in Ethiopia. Addis Ababa: IFPRI.

[5] Bonin, M., Cattan P., 2006. Convergences and differences between the objectives of the financial support facilities and those of the farmers: the case of fallow periods in banana Production of Guadeloupe. Fruits, 2006, 61, 9-23.

[6] Dasgupta, Satadal, 1989. Diffusion of Agricultural Innovations in Village India. Wiley Eastern Limited, New Delhi. 231p.

[7] Demeke, M. (2012). Analysis of incentives and disincentives for maize in Ethiopia. Technical notes series, MAFAP. Rome: FAO.

[8] Demissew et al., 2013,: Farmers' Perceptions of Maize Production Systems and Breeding Priorities, and Their Implications for the Adoption of New Varieties in Selected Areas of the Highland Agro-Ecology of Ethiopia: Journal of Agricultural Science; Vol. 5, No. 11. 
[9] J. Becerril and A. Abdulai, 2010, The impact of improved maize varieties on poverty in Mexico: A Propensity score approach. World Development, 2010, 38(7): 10240.1016/j.worlddev.2009.11.017

[10] Lapar, M. L. A. and Ehui, S. 2004. Factors affecting adoption of dual-purpose forages in the Philippine uplands. Agricultural Systems 81: 95-114.

[11] McCann, J. C. (2005). Maize and grace: Africa's encounter with a newworld crop, 1500-2000. Cambridge: Harvard University Press.

[12] Nkonya, E., T. Schroeder and D. Norman, 1997. Factors affecting adoption of improved maize seed and fertilizer in Northern Tanzania. Journal of Agricultural Economics, 4:1-12.

[13] Oladele, O. L., and O. P Fawole, 2007. Farmers' Perception of the Relevance of Agricultural Technologies in South-Western Nigeria. Department of Agricultural Extension and Rural Development, University of Ibadan, Ibadan. J. Hum. Ecol. 21(3):191-194.
[14] Rahmeto Negash, 2007. Determinants of improved haricot bean production package in Alaba special wored, Southern Ethiopia. M.Sc. Thesis Presented To School of Graduate Studies of Haramaya University.

[15] Tsedeke et al, 2005: Factors that transformed maize productivity in Ethiopia.

[16] Twumasi-Afriyie, et al, (2002). Development and Improvement of Highland Maize in Ethiopia. In M. Nigusse, \& D. Tanner (Eds.), Proceedings of the Second National Maize Workshop of Ethiopia, 12-16 November 2001 Addis Ababa, Ethiopia (pp. 31-38). Addis Ababa: EARO and CIMMYT.

[17] Woreda Office of Agricultural and Rural Development (WOARD), 2016. Activity performance reports. Unpublished document, Toke kutaye, Ethiopia. 